\title{
ESTUDIOS
}

\section{La participación ciudadana en el sector de la salud: un estudio cualitativo de la realidad chilena'}

\section{Andrea Peroni}

Palabras clave: Participación, derechos, ciudadanía, salud, Chile.

Key words: Participation, rights, citizenship, health, Chile.

Mots-clés: Participation, droits, citoyenneté, santé, le Chili.

\section{Introducción}

El tema de la participación ciudadana, sin lugar a dudas, es un campo de interés para la sociología y las políticas públicas. Se entiende por participación ciudadana la necesidad de empoderamiento por parte de la ciudadanía para ejercer un rol activo; contrario a un rol pasivo, receptor de políticas y medidas gubernamentales (Escobar, 2001).

La participación vinculada a un ámbito concreto es un campo de trabajo e investigación real, por ello es de interés para el presente estudio observar cómo se desarrolla, detiene, reformula y genera empoderamiento en el ámbito de la salud. Dicho ámbito se refiere a una de las necesidades básicas de la población, donde

1 Ponencia presentada en el Congreso Latinoamericano de Sociología ALAS, Guadalajara, México, Agosto 2008. Mesa: Sociología de la Salud. Institución patrocinante: Universidad de Chile.

${ }^{2}$ Académica del Departamento de Sociología de la Universidad de Chile. Facultad de Ciencias Sociales. Consultora en temas de Planificación y Evaluación, Ministerio de Hacienda, Chile; Instituto Latinoamericanos de Planificación Económica y Social (ILPES), CEPAL, Naciones Unidas. 
las decisiones que se tomen a nivel político institucional afectan directamente sus vidas. La condición de salud o enfermedad no es una opción racional, por consiguiente no es una alternativa el acceder o no a un servicio de salud, al presentarse una determinada patología. La participación ciudadana en el ámbito de la salud, justamente acrecienta la salud individual y comunitaria. Además supera las alternativas actualmente naturalizadas de respuesta a las necesidades insatisfechas, como son la acción individual y el mercado.

En Chile, la participación ciudadana fue planteada por el ex Presidente Lagos en su Instructivo Presidencial del año 2000. En él, Lagos destaca la importancia de la misma para el buen funcionamiento del sistema democrático y, asimismo, asevera que en éste plano se requiere un gobierno que abra la participación hacia una sociedad civil activa. Es así, como el Ministerio de Salud (MINSAL,2006a) y en especial el Servicio de Salud Metropolitano Sur (SSMS,2006) se planteó, tres objetivos sobre los cuales trabajar el tema de la participación ciudadana: el fortalecimiento de las redes entre los centros de salud y la comunidad a la cual atiende; la generación de Cuentas Públicas participativas; y el fortalecimiento de las Oficinas de Información, Reclamos y Sugerencias (OIRS).

En el contexto de los objetivos planteados por el SSMS, el presente trabajo pretende responder la siguiente pregunta ¿̇cuáles son las características y potencialidades de la participación ciudadana en el ámbito de la salud pública?

Para el desarrollo del estudio se utilizó la metodología cualitativa, mediante el análisis documental (institucional - normativas) y se aplicaron las técnicas de entrevistas en profundidad individuales y grupales, dirigidas a encargados del programa de participación en consultorios y hospitales y representantes de las organizaciones comunitarias. Se empleó la técnica de la observación participante en el relato de las Cuentas Públicas en los organismos de salud, así como en las sesiones de los Consejos de Salud ${ }^{3}$.

${ }^{3}$ El trabajo de campo se realizó en el contexto de la elaboración de diagnósticos sociales, en el curso de Programación Social, de la Carrera de Sociología de la Universidad de Chile., efectuado por los alumno/as bajo la coordinación de la docente: Andrea Peroni. El presente artículo corresponde a una relectura de la información generada, recogiéndose un segmento del trabajo allí realizado. En la presente ocasión aprovecho para agradecer a los participantes en la investigación su dedicación y profesionalismo, tanto a los estudiantes como a los entrevistados. Asimismo agradezco los comentarios realizados por las colegas Laura Guardia y Andrea Canales. 
La muestra ${ }^{4}$ estuvo compuesta por los encargados de participación y la comunidad representada en los Consejos de Salud del Centro de Salud Familiar Amador Neghme y La Feria, de la comuna de Pedro Aguirre Cerda y del Hospital Pino, en la comuna de San Bernardo, y el Complejo Asistencial Barros Luco en la comuna de San Miguel. Se realizaron 16 entrevistas. La selección de los entrevistados se conformó mediante cuotas representativas de los roles que desempeñaban en relación a las dinámicas participativas.

El sector geográfico corresponde a la zona sur de la Región Metropolitana, específicamente del Gran Santiago, siendo comunas de sectores caracterizados por un nivel socioeconómico bajo. Fue urbanizado mediante ocupaciones populares de terreno fiscales, durante la década de los sesenta y por traslados forzosos efectuados durante el Gobierno Militar.

En el análisis se profundiza en la percepción ${ }^{5}$ de los entrevistados sobre las categorías a través de las cuales se puede observar la participación: los derechos y deberes, la representatividad, los recursos, y la toma de decisiones. En las conclusiones se vinculan las categorías con los niveles de la participación, pudiéndose observar el despliegue de la gradiente tanto en la normativa institucional, en la implementación pública, como en la ciudadanía. En dicha triada (la normativa institucional y sus protagonistas -funcionarios públicos y ciudadanía-), las intencionalidades son desparejas y será la sociedad civil la que "empuja" hacia niveles más cercanos al empoderamiento.

\section{Marco Analítico: ¿de qué participación estamos hablando?}

Un estudio de estas características debe revisar tres aspectos sobre la participación ciudadana: la revisión conceptual -la cual no es unívoca- desarrollada por el campo común de la sociología y la ciencia política; el estado de la cuestión en el tema participación y políticas publicas en Chile; y finalmente la temática en el ámbito de la salud pública ${ }^{6}$. Estos tres ejes son los que permitirán encontrar una

\footnotetext{
${ }^{4}$ En el anexo se detalla la distribución de los entrevistados según función e institución.

${ }^{5}$ Se ilustra dicha percepción mediante la inclusión de las citas textuales extraídas de las entrevistas, colocándose entre párrafos o en cuadros analíticos, bajo tipografía cursiva.

${ }^{6}$ En el área de la salud el tema de la participación ha sido estudiado por C. Celedón y R. Orellana (2003), analizando el tipo de participación y el tratamiento de la misma durante el proceso de diseño
} 
adecuada respuesta a la pregunta planteada en este apartado: $\dot{\partial}$ de que participación estamos hablando?

\section{I.Acerca del concepto de participación ciudadana}

Según Touraine, la ciudadanía apunta a la idea que los gobernados quieran elegir a sus gobernantes, quieran participar en la vida democrática, tengan una conciencia de pertenencia a la sociedad política (MSGP, 2001). La ciudadanía se vincula a la idea de derechos y deberes de las personas con el Estado y con la comunidad política ${ }^{7}$, por ende con el espacio público y la gestión del mismo.

La participación va de la mano con la ciudadanía, ya que ésta es el mecanismo para ejercerla. La participación se desarrolla en el espacio público, espacio común donde se actúa, representa y exige mayor democracia.

Ahora bien la participación no es homogénea per se, ni entre sus participantes, objetivos y metas. Existen distintos tipos de participación, ello requiere efectuar un análisis más detallado, a fin de comprender la dinámica del fenómeno en estudio. A continuación se presenta una adaptación de la tipología sobre la gradiente que puede encontrarse en la participación de menor a mayor ingerencia en el espacio público. La tipología toma como referencia las propuestas de C. Serrano y D. Raczynski, (1998), y de A. Canales y R. Márquez (2006), generándose la siguiente escala:

\section{Participación instrumental}

Reúne la participación que tiene por propósito la satisfacción de necesidades básicas y aquella que utiliza la oferta tal cual viene predefinida desde los canales institucionales correspondientes. Es un tipo de participación pasiva.

de la reforma del sector salud; D. EscOBAR R. (2001), analizando la evolución de la participación en los programas de promoción de la salud; MARSHALL ET AL (1900) sobre la participación a nivel de consultorios. Sin embargo, ninguno de los estudios analiza el tema de la participación en salud, en el contexto de la nueva Ley 19937, Autoridad Sanitaria (2004).

7 La evolución de los derechos de la ciudadanía es, en gran medida la evolución de la relación del Estado y la sociedad. Para T. MARSHALL (1949) supone tres tipos de derechos a lo largo de la historia: una ciudadanía civil (siglo XVIII), libertad de la palabra, pensamiento y acción, liberad de propiedad y de contrato y el derecho a la justicia. De allí surgen los derechos civiles, construidos por las libertades básicas y los derechos a la propiedad y la justicia. Una ciudadanía política (siglo XIX) que se refiere al derecho a participar en el ejercicio del poder y el derecho a elegir y ser elegido. Una ciudadanía social (siglo XX) asociada a la expansión del Estado de Bienestar. 


\section{Participación informativa}

Se refiere al tipo mas básico entre los diferentes niveles de la participación, y se desarrolla mediante el deseo de los ciudadanos por conocer sus deberes y derechos. También puede ser el tipo de participación donde el Estado da a conocer los derechos y deberes a la ciudadanía. Este proceso tiene implícito un límite, cual es la real disponibilidad de la información pública y que esta sea de calidad, es decir, clara, pertinente, oportuna y precisa.

III. Participación consultiva

Se refiere a dos modalidades de participación, en ambas se caracteriza por la consulta que efectúa la autoridad, sobre una problemática determinada, a la ciudadanía. Puede ser vinculante con la decisión a tomarse, o no vinculante, siendo una consulta tipo informativa. Se visualizan as experiencias tipo cabildos o consultas locales, con una interacción activa autoridad-población, que respeta la identidad local y abren espacios de conversación y consulta.

\section{Participación gestionaria}

Combina la participación asociada a la toma de decisiones y la participación que redunda principalmente en beneficios concretos de satisfacción de necesidades básicas. Esta modalidad considera a los beneficiarios como gestores de programas públicos para dar respuesta a problemas locales o sectoriales. Genera capacidades en la comunidad. Supone que existe liderazgo social e información para actuar como interlocutor de las agencias estatales. La limitación se encuentra en el hecho que puede ser incorporada la ciudadanía a la gestión, pero no lo estuvo en el diseño o en la toma de decisiones.

\section{Participación como control}

Se refiere a la participación como control ciudadano que alude a la posibilidad de emprender acciones de fiscalización de la gestión pública. La ciudadanía puede participar en instancias de evaluación o auditoría de los asuntos públicos, favoreciendo la apropiación de los público estatal.

\section{Participación como empoderamiento}

Combina la participación en la toma de decisiones, en la gestión y en el control, pero además concerta voluntades y forma alianzas. Va más allá de acciones 
particulares ya que se encamina al fortalecimiento del empoderamiento por parte de la ciudadanía. Es un tipo de participación en la cual la comunidad adquiere destrezas y capacidades, fortalece sus propios espacios y organizaciones y actúa con un sentido de identidad y de comunidad propio. A la vez logra proponer temas al Estado, e incrementar su capacidad de negociación e interlocución con el sector público.

Cada tipo de participación habla de desniveles entre lo permitido desde el Estado y lo posible desde la ciudadanía. La tensión esta presente entre el tamaño de la apertura pública y la madurez participativa ciudadana, quedando muchas veces estrecha o sobrepasada la relación. Mediatizada por la institucionalidad que da paso a la implementación.

\subsection{Acerca de la participación y las políticas públicas en Chile}

En Chile, la relación entre participación y las políticas públicas ha sido suficientemente estudiado (Serrano 1998, Raczynski 1998, Garcés 1999, Valdés 1999, Espinoza V.2004, De la Maza 2004, etc.). No obstante, a efectos de una mejor comprensión del tema, se mencionaran los hitos de dicha relación a partir de la década de los noventa.

Cuando la Concertación asume la democracia se establece un nuevo tipo de relación entre la sociedad civil organizada y el Estado, el nuevo cauce será a través de la incorporación de la participación a la agenda de gobierno. Se delimita su campo de acción, de tal forma que la participación queda restringida a la acción electoral, al apoyo a la agenda gubernamental y a la coejecución de nuevos programas sociales.

La década de los noventa se inicia con la democratización de las Juntas de Vecinos. Como resultado se obtiene un amplio contingente de dirigentes locales, provenientes de Juntas de Vecino y Uniones Comunales, las que con el transcurso del tiempo comienzan a decaer. En 1996 se dicta una nueva ley que las regula, a juicio de la Maza (2004), dicha ley también las debilita ya que no aborda el tema del financiamiento o de los espacios de participación institucional de dichas organizaciones. No obstante, el gobierno le encarga a la División de Organizaciones Sociales (DOS) del Ministerio Secretaría General de Gobierno que actúe como la instancia de vinculación con las organizaciones territoriales, a fin de institucionalizar y desarrollar el vínculo Estado-sociedad civil. 
En relación a la oferta pública gubernamental se observa que los elementos de participación presentes en los programas eran del tipo consultivo/ instrumental. Muy pocos programas consideraban la participación como un objetivo vinculado a la ciudadanía, con valor "per se"

Un nuevo hito importante se encuentra en el gobierno del Presidente Lagos, cuando en el 2000 envió a los ministerios un "Instructivo Presidencial" en el cual señalaba las orientaciones e indicaciones para el desarrollo de la participación de los ciudadanos en todos los ámbitos de la vida nacional. En dicho Instructivo se señala que la participación ciudadana es la dimensión fundamental de todo sistema democrático, ya que contribuye a que los derechos y deberes institucionalmente establecidos sean efectivamente reconocidos y ejercidos. Además la participación tiene la virtud de contribuir a generar una relación de colaboración y respeto mutuo entre el Estado y la ciudadanía. Favorece el fortalecimiento de la sociedad civil y permite una mayor legitimidad de las políticas públicas. Los principios orientadores para el desarrollo de esta temática se basan en el Buen Trato, Igualdad de Oportunidades, Respeto a la Autonomía y Diversidad de las Organizaciones, Transparencia de la Gestión y Orientación al Ciudadano.

El Instructivo fue incorporándose en las instituciones gubernamentales fundamentalmente a través del nombramiento del encargado del tema a nivel ministerial, y luego con el desarrollo de distintos tipos de medidas ${ }^{10}$. Este Instructivo fue acatado por toda la institucionalidad pública. No obstante, según EsPINOZA (2004) la respuesta de las agencias gubernamentales al Instructivo comienza con la creación de condiciones

\footnotetext{
${ }^{8}$ Según el análisis realizado por SERRANO (2001), a través de la revisión de 151 programas públicos en operación en al segunda mitad de los años noventa, alrededor de un $50 \%$ de estos programas poseían algún componente participativo. En Canales A. (2006) Apuntes de Clase. Políticas Públicas, $\mathrm{UAH}, 2006$.

9 Gobierno de Chile. Instructivo Presidencial sobre Participación Ciudadana. Oficio № 030 del 07-12-2000.

10 Por ejemplo, el Programa de Participación Ciudadana surge como oferta programática a partir del "Instructivo presidencial sobre participación ciudadana" y del "Plan para el fortalecimiento de las organizaciones de la sociedad civil" ambos instrumentos dados a conocer durante el gobierno del ex presidente Lagos, en los cuales se planteaba la necesidad de que el sector público generara espacios, entregara información y estableciera mecanismos para acoger las "preocupaciones, necesidades y propuestas provenientes de la ciudadanía". El Plan contemplaba medidas en cinco áreas temáticas: (i) desarrollo de un marco jurídico; (ii) financiamiento para las Organizaciones de la Sociedad Civil (iii) fortalecimiento institucional de las organizaciones; (iv) promoción del trabajo voluntario; y (v) cooperación entre Estado y sociedad civil, en directa relación con la ejecución del Instructivo presidencial de participación ciudadana.
} 
para la participación, sigue con facilidades de contacto con los usuarios, circulación de información y establecimiento de acuerdos de trabajo (Espinoza, 2004). Como se puede apreciar lejos se encuentra de una institucionalización del control ciudadano, a pesar de la política de participación ciudadana del actual gobierno, expresada en la Agenda Pro-Participación Ciudadana (APPC), presentada por la presidenta Michelle Bachellet, el día 29 de septiembre de 2006.

La necesidad de profundizar la democracia resulta fundamental para los gobiernos de la Concertación, que el Estado reconozca tanto los derechos como los deberes de los ciudadanos, como también el ejercicio y uso de quienes son los titulares de estos derechos. Para ello resulta indispensable promover desde el Estado los mecanismos que posibiliten la coexistencia con una sociedad civil organizada e interesada en las cuestiones públicas. En dicho contexto se encuentra, en la actualidad en el Congreso el Proyecto de Ley de Participación enviado por el ex Presidente Lagos, a fin de su mandato y mantenida su importancia por la Presidenta Michelle Bachelet.

La propuesta final presentada al Congreso acota los mecanismos de participación a los niveles de consulta e información, sin incluir el plano local. El enfoque del proyecto pone el énfasis en mecanismos de transparencia e información, como un componente de la modernización de la gestión, sin un concepto claro de fortalecimiento de la sociedad civil. (ESPINOZA, 2004)

\subsection{Acerca de la participación y el sector salud}

En la actualidad el objetivo del Ministerio del Salud (MINSAL) es Contribuir a elevar el nivel de salud de la población desarrollando armónicamente un sistema de salud centrado en las personas, fortaleciendo el control de los factores que puedan afectar la salud y reforzando la gestión de la red nacional de atención, para que acoja oportunamente las necesidades de las personas, con la obligación de rendir cuentas a la ciudadanía promoviendo la participación para el ejercicio de sus derechos y deberes ${ }^{11}$.

Dicho objetivo presenta de manera explícita la intención de promover un tipo de participación del más alto nivel cercana al empoderamiento de la ciudadanía.

Pero veamos cuál es el contexto en el que se inserta el objetivo ministerial, para comprender con mayor precisión el alcance del mismo.

\footnotetext{
${ }^{11}$ www.minsal.d
} 
A partir de mayo del año 2000, el Presidente Lagos inicia el proceso de Reforma de la Salud ${ }^{12}$. Bajo la misma orientación del Instructivo Presidencial antes citado, se concibió un importante acento en la participación ciudadana como estilo de diseño de la política publica de salud y de su implementación mediante mecanismos de control social (CELEDón, 2003)

La Secretaría Ejecutiva de la Comisión Interministerial para la Reforma de la Salud plantea los siguientes lineamientos estratégicos: La salud de las personas es un producto de la vida en sociedad y cada sociedad tiene problemas de salud que le son inherentes y cuya solución requiere de enfoques integrales. Un enfoque integral de la salud exige una participación activa, informada y responsable de cada persona y de la comunidad organizada. Los ciudadanos deben opinar entre los cauces que le permitan expresar sus aspiraciones e inquietudes y participar en la orientación de los servicios de salud que los atienden, sean estos públicos o privados. La salud integral y participativa es un compromiso del Estado (Celedón y Orellana, 2003). Dicha orientación se puede visualizar en las múltiples instancias de participación propuestas a nivel legislativo (Régimen de Garantías en Salud; Consejo Consultivo del Régimen de Garantías en Salud; Régimen de calificación de los establecimientos hospitalarios; Consejo Asesor de la Secretaría Regional Ministerial y Consejo de la Red Asistencial).

La Reforma se institucionaliza a través de la Ley 19937 Autoridad Sanitaria. Publicada por el Diario Oficial el 24 de febrero del 2004. En relación al tema del estudio es importante resaltar los siguientes aspectos, que nos permitirán evaluar el tipo de participación ciudadana que se propone versus el tipo de participación que se desarrolla en el Servicio de Salud Metropolitano Sur (SSMS).

La normativa en materia de Atención de Usuarios y Participación Social menciona lo siguiente:

\footnotetext{
${ }^{12}$ La Reforma de Salud en marcha busca reorganizar el sistema de seguridad social en salud de forma tal que los recursos sean asignados en función de las necesidades sanitarias de la población. Los elementos centrales de la reforma son: a) la determinación de Objetivos Nacionales de Salud para el Sistema público y privado, b) un cambio en el modelo de atención desde un énfasis en lo curativo hacia el fomento de la salud y la prevención de la enfermedad; c) la incorporación de criterios de equidad mediante el establecimiento de garantías exigibles para toda la población, de acceso, calidad, oportunidad de atención y de protección financiera frente a las urgencias y problemas de salud que tienen un mayor impacto en la calidad de vida de las personas y sus familias, y d) un cambio en el modelo de regulación y gestión del sistema. Las garantías exigibles se irán extendiendo en la medida que el país disponga de mayores recursos y el sistema de salud se vaya ajustando a la nueva forma de funcionamiento. (Celedón y Orellana, 2000)
} 
a) Establecer mecanismos de orientación e información al usuario, así como diseñar e implementar sistemas de recepción de opiniones, sugerencias, reclamos y felicitaciones de los usuarios y de la comunidad en general y un sistema de respuesta o resolución según corresponda, de acuerdo a las normas técnicas que imparta el Ministerio de Salud;

b) Proponer y mantener instancias permanentes de participación social que permitan recibir la opinión de los usuarios y la comunidad sobre la calidad de las prestaciones que se otorgan y propuestas para su mejoramiento;

c) Evaluar continuamente el grado de satisfacción de los usuarios con la calidad de la atención prestada por los establecimientos de la Red Asistencial, de acuerdo a las normas técnicas que imparta el Ministerio de Salud. (Ley 19937 Autoridad Sanitaria, párrafo I de la Subdirección de Gestión Asistencial. Artículo 21.-)

Dichas funciones estarán a cargo de la Subdirección de Gestión Asistencial, la que dependerá del Director de cada Servicio de Salud, por consiguiente se ubica al más alto nivel de la administración regional de salud.

No obstante, como se puede apreciar la participación que se exige instaurar es de tipo informativo fundamentalmente, alternado con consultivo sin vinculación, aunque el carácter consultivo esta dado por el derecho al reclamo de los pacientes. $Y$ finamente "monitorear" la satisfacción de los usuarios, pero como una medida impulsada por el MINSAL, para informarse sobre eficacia en la gestión, vinculado a la modernización del Estado, más que al desarrollo de la ciudadanía.

La Subsecretaría de Redes Asistenciales, a través de la División de Gestión de Red Asistencial, designó a un Equipo Transversal para entregar las orientaciones sobre los Compromisos de Gestión, específicamente el compromiso N7, denominado "Participación Social", siendo el objetivo central de dicho compromiso desarrollar estrategias de Participación Social en la Red de Salud (Subsecretaria de Redes Asistenciales, 2006)

Ahora bien, en la operacionalización de dicho objetivo se puede observar cuál es el modelo de participación que promueve el MINSAL, en la cotidianeidad de su accionar. Los objetivos específicos, son los siguientes:

1. Elaborar una cuenta pública en forma participativa.

2. Gestionar las solicitudes ciudadanas que los ciudadanos hacen en las OIRS.

3. Establecer y ejecutar planes de acción conjunto entre los establecimientos de la red asistencial y la red comunitaria. 
En relación al objetivo $n^{\circ} 1$, se pretende monitorizar la participación de la comunidad en la elaboración de la cuenta pública y la planificación de su presentación. Se busca aportar a la transparencia y control social de la gestión pública a través de un trabajo conjunto entre los directivos de cada establecimiento y las redes comunitarias y sociales de su territorio. Los responsables de dar cuenta de este proceso son los directores de los Servicios de Salud y de los establecimientos que conforman la red asistencial en todos sus niveles. Sería conveniente que en este proceso se incorporen también los establecimientos de Atención Primaria Municipal.

En relación al objetivo $n^{\circ} 2$, se pretende que los establecimientos junto con el Consejo de Desarrollo (u otras denominaciones) realicen análisis de las solicitudes ciudadanas y elaboren planes de intervención a corto, medianoy/o largo plazo. Las Oficinas de Informaciones Reclamos y Sugerencias ${ }^{13}$ (OIRS) reciben las solicitudes ciudadanas, las que son gestionadas al interior de los establecimientos. De manera participativa, se analizan los reclamos tipificados con antelación, se compara con el año anterior y se generen planes de intervención a corto, mediano y/ o largo plazo, sobre las debilidades detectadas. Al final del año en curso, se elaborará una evaluación de lo realizado con respecto a los planes de intervención en forma conjunta con el Consejo de Desarrollo.

Asimismo según la Ley de Base de Procedimientos Administrativos que establece los plazos para la solución de los reclamos que realiza la ciudadanía en los establecimientos públicos, este año se avanzará en la solución de los reclamos dentro de los plazos establecidos legalmente (no podrá excederse los 180 días).

En relación al objetivo $n^{\circ} 3$, se busca incentivar el trabajo conjunto entre los equipos de salud y las organizaciones comunitarias que trabajan vinculadas a los establecimientos. Para tales efectos se propicia la utilización de diferentes metodologías como mesas territoriales, diagnósticos y presupuestos participativos, consultas ciudadanas, etc. Es necesario pensar el compromiso incorporando las competencias y ámbitos de acción de las organizaciones que mantienen un vínculo permanente con el establecimiento y Servicio de Salud. En este sentido, el Servicio de Salud deberá establecer sus propios planes de acción en conjunto con organizaciones comunitarias que sean representativas (por ejemplo, Consejos de Desarrollo del Servicio, Federaciones de Uniones Comunales, entre otros). Se espera que la re-

\footnotetext{
${ }^{13}$ La OIRS es un espacio de escucha mediante el cual se acogen las solicitudes ciudadanas, que vincula las demandas ciudadanas con las reparticiones de salud pública, dando respuesta a sus inquietudes. También permite abrir un espacio de participación eficiente entre los ciudadanos y el Ministerio de
} Salud (www.minsal.cl). 
dacción del compromiso sea conjunta y exprese la opinión de los firmantes. Esta meta tiene relación con la certificación y reconocimiento de las competencias de las organizaciones comunitarias o redes comunitarias en cuidados en salud. Las áreas a desarrollar pueden ser apoyo a la gestión, ejercicio de derechos ciudadanos, recuperación, promoción, rehabilitación y prevención, entre otras.

Si se efectuara un análisis sobre los objetivos específicos en relación a los tipos de participación se obtendría la matriz recogida en la tabla $\mathrm{n}^{\circ} 1$.

TABLA N $N^{\circ}$ I. Tipos de participación presentes en la formulación de los Compromisos de Gestión

\begin{tabular}{|l|c|c|c|}
\hline $\begin{array}{l}\text { Tipos de } \\
\text { participación }\end{array}$ & $\begin{array}{l}\text { Elaborar una } \\
\text { cuenta públi- } \\
\text { ca en forma } \\
\text { participativa. }\end{array}$ & $\begin{array}{l}\text { Gestionar las } \\
\text { solicitudes ciu- } \\
\text { dadanas que los } \\
\text { ciudadanos ha- } \\
\text { cen en las OIRS. }\end{array}$ & $\begin{array}{l}\text { Establecery ejecutar pla- } \\
\text { nes de acción conjunto } \\
\text { entre los establecimien- } \\
\text { tos de la red asistencial } \\
\text { y la red comunitaria. }\end{array}$ \\
\hline $\begin{array}{l}\text { Participación } \\
\text { instrumental }\end{array}$ & & & \\
\hline $\begin{array}{l}\text { Participación } \\
\text { informativa }\end{array}$ & $\checkmark$ & $\checkmark$ & $\checkmark$ \\
\hline $\begin{array}{l}\text { Participación } \\
\text { consultiva }\end{array}$ & $\checkmark$ & $\checkmark$ & $\checkmark$ \\
\hline $\begin{array}{l}\text { Participación } \\
\text { gestionaría }\end{array}$ & $\checkmark$ & & $\checkmark$ \\
\hline $\begin{array}{l}\text { Participación como } \\
\text { "accountability" }\end{array}$ & $\checkmark$ & & $\checkmark$ \\
\hline $\begin{array}{l}\text { Participación como } \\
\text { empoderamiento }\end{array}$ & & & $\checkmark$ \\
\hline
\end{tabular}

Fuente: elaboración propia

Cabe recalcar que la matriz presenta la intencionalidad pública, sobre el tema de la participación, y de acuerdo a ello se puede observar que el objetivo $n^{\circ} 2$ es el que propone un menor avance en participación, dejando acotado a la OIRS la responsabilidad de acoger, tabular y analizar los reclamos y felicitaciones, 
así como su solución. El objetivo $\mathrm{n}^{\circ} 1$ avanza hasta el nivel de control social mediante la participación y seguimiento de la Cuenta Pública. Y finalmente el objetivo $n^{\circ} 3$ otorga una visión orientada hacia el pleno ejercicio ciudadano en el área de salud.

La participación instrumental no se incorpora porque no se analiza la entrega de bienes y servicios sino el tipo de objetivos a lograr, como compromiso de gestión publica.

Ahora bien, como el presente estudio pretende conocer la realidad sobre el tipo de participación vivida en uno de los 29 Servicios de Salud, es conveniente incorporar algunas características del nivel regional que nos convoca, el Servicio de Salud Metropolitano Sur.

El SSMS ${ }^{14}$ señala en su misión lo siguiente: Ser una red de salud integrada cuyo objetivo principal es lograr el mejor impacto sanitario en nuestra población asignada, mediante una gestión de excelencia, con un trabajo coordinado y centrado en las necesidades de nuestros usuarios, fomentando la participación social, el desarrollo de las personas que trabajan en la organización, la equidad y el uso eficiente de los recursos de la red. ${ }^{15}$

El estado de cumplimiento de la misión se puede apreciar en lo siguiente: todos los hospitales y siete consultorios están acreditados con la carta de los derechos del paciente, y todos los consultorios y hospitales cuentan con oficinas de información y recepción de reclamos o felicitaciones (OIRS). Si bien estos son antecedentes formales, indican que se han puesto en marcha las orientaciones tanto del MINSAL, como del SSMS. No obstante, cabe preguntarse si dichas medidas son suficientes per se y cual es el nivel de cumplimiento de los objetivos específicos del Compromiso de Gestión № 7.

Desde otra perspectiva, el vínculo del sector salud con la comunidad presenta los siguientes hitos. Desde 1992 se desarrolló el Programa de Promoción de la Salud,

${ }^{14}$ El SSMS corresponde a uno de los seis servicios de salud metropolitanos. Su superficie total es de $1.176 \mathrm{kms}^{2}$; cobertura 158.335 habitantes y 11 comunas de la zona sur (San Joaquín; San Miguel; Pedro Aguirre Cerda; Lo Espejo; La Cisterna; El Bosque; San Bernardo; Calera de Tango; Buin; Paine y La Granja); coordina 29 consultorios de Atención Primaria; 12 SAPUs; 4 COSAM; 14 postas rurales; 6 establecimientos hospitalarios (Complejo Asistencial Barros Luco; Dr. Lucio Córdova; Exequiel González Cortés; El Pino; El Peral; San Luís de Buin). Participan: 4.487 funcionarios en los hospitales y 2.250 funcionarios en la atención primaria.

${ }^{15}$ www.ssms.d 
se promovieron los Concejos Locales de Salud y de Desarrollo de los Hospitales. Estos programas han instalado una instancia de apoyo a la gestión y a la salud preventiva. Actúan por medio del trabajo voluntario, aportes financieros y materiales y organización de la comunidad. Paulatinamente se orientó el trabajo en común hacia la "promoción de la salud", lo que a juicio de Gonzalo de la Maza (2004) reduce la participación a organizar y movilizar personas para actividades preventivas (campañas contra la obesidad, tabaquismo, caminatas saludables, etc).

Actualmente existen una amplia red de organizaciones y grupos que colaboran en la acción de salud con enfoques de promoción, pero el traspaso de ese estilo a la nueva propuesta, según la Reforma en Salud, genera desafíos no contemplados en los instructivos ministeriales, existen modalidades incorporadas tanto en el personal de salud como en la comunidad organizada que tensiona la viabilidad de ejercer un tipo de participación que responda a niveles avanzados.

Por una parte la participación requiere que el sector público tenga la apertura, genere la información y establezca espacios y mecanismos que acojan las preocupaciones, necesidades y propuestas de la ciudadanía y pareciera ser que a nivel formal, dicha apertura esta establecida. No obstante, esto no es suficiente y amerita conocer "in situ" como es la dinámica institucional frente al tema de la participación ciudadana.

Por otra parte, la participación necesita de una ciudadanía que se involucre en las cuestiones públicas, con organizaciones fuertes que representen toda su diversidad. Y este aspecto de la relación también amerita ser estudiado, para poder evaluar si efectivamente se cuenta con una ciudadanía "colaborativa" o "empoderada".

\section{La participación ciudadana en el Servicio de Salud Metro- politano Sur}

El análisis de la participación ciudadana en el área de salud se efectuó en base a entrevistas ${ }^{16}$ realizadas en los Centros de Salud Familiar Amador Neghme y La Feria, ubicados en la comuna de Pedro Aguirre Cerda, así como en el Hospital El Pino y en el Complejo Asistencial Barros Luco. Dichas entrevistas se realizaron a los encargados institucionales de participación y a los representantes de la

${ }^{16}$ En el cuadro $\mathrm{N}^{\circ} 1$ del Anexo se detallan los códigos que identifican a los entrevistados. Dichos códigos serán las referencias que permitan contextualizar los contenidos citados en el análisis que se realiza en el presente apartado. 
comunidad en los consejos de salud respectivos. Por consiguiente, el análisis que se presenta da cuenta de las distintas perspectivas involucradas, la pública y la sociedad civil, sobre las temáticas constitutivas del concepto de participación a fin de poder caracterizar los tipos de participación antes presentados.

Las categorías que se incluyen en el análisis tienen relación con la posibilidad de observar los distintos niveles, instrumentos e instancias sobre cómo se desarrolla la participación en salud. Dichas categorías permiten apreciar las características del proceso de empoderamiento o no, por parte de la ciudadanía, así como los espacios que abre la institucionalidad para tal efecto, siendo las siguientes: derechos ciudadanos; deberes ciudadanos; representatividad; recursos y toma de decisión. A continuación se presenta el análisis de los mismos visualizados en un eje cartesiano: actores (institucionales / sociedad) y nivel de atención institucional (hospital-complejo asistencial / consultorios-centros de salud familiar).

\section{I. Sobre el ejercicio de derechos ciudadanos en salud}

A partir del plan AUGE ${ }^{17}$, se garantiza el acceso a la salud, ello se traduce en la atención a 56 patologías, según el protocolo médico aprobado para cada uno. Esta nueva situación ha provocado que se asuma el cumplimiento del Plan como un derecho de los pacientes y desde esta perspectiva se pone en marcha una serie de acciones a fin de lograr tal objetivo. Así en el nivel terciario se proponen entregar a ellos -los usuarios- lo que es capacitación... una orientación sobre los derechos ciudadanos en el AUGE, sobre los derechos de los pacientes, un poco en la onda de decir miren, estos son sus derechos, conózcanlos para que puedan hacerlos exigibles. Y complementar dicha actividad con dirigir acciones hacia los funcionarios públicos sobre el mismo tema; este es el cuarto año que deberíamos tener gente capacitándose en esto, los derechos del paciente, los reclamos y todo ello. (HEP-F). Dichas acciones abarcan tanto a los usuarios como a los funcionarios, a fin que ambos puedan estar informados sobre las nuevas temáticas sobre las que deben interactuar.

\footnotetext{
${ }^{17}$ Es el Acceso Universal con Garantías Explícitas en Salud, un derecho establecido por ley tanto para los beneficiarios de FONASA (Fondo Nacional de Salud) como de ISAPRE (Instituciones de Salud Previsional). Desde el 1 de Julio del 2005, día de la entrada en vigencia de la Ley AUGE, se garantiza el acceso a la atención de salud oportuna, de calidad y con protección financiera. El AUGE contempla, 40 enfermedades, que son las de mayor impacto en la salud y presupuesto familiar de la población. Las condiciones de acceso, oportunidad, calidad y protección financiera se encuentran en la resolución № 574 del Ministerio de Salud, año 2004. En la actualidad se denomina AUGE o GES, Garantías Explicitas de Salud, y se ha aumentado la cobertura a 62 patologías (enero, 2008).
} 
Pero el tema de los derechos va de la mano con la posibilidad de ejercerlos, entonces es importante darles a conocer sus derechos, usted tiene derechos a reclamar y a información, o en la mañana cuando ingreso a un paciente, tome, aquí hay una oficina de reclamos señora, si a usted la atendemos mal tiene derecho a reclamar, tiene derecho a recibir una respuesta por escrito y a tener una solución de su problema en 180 días (HEP-F). Ello significa también analizar los reclamos con los usuarios, para que sepan para dónde van, que ellos conozcan que tengo un problema grave en urgencia, no es que queramos atender mal...para que ellos nos ayuden (HEP-F). Para quienes están encargados de las OIRS todos los reclamos son apropiados, porque en alguna parte falló el sistema...o falló la información médica, o falló la información administrativa o falló la oficina de informaciones, o falló el médico, falló la enfermera... (HEP-F). De esta manera formalmente esta dada la instancia donde poder ejercer los derechos, al menos los derechos ejercidos a través del reclamo, las sugerencias y también las felicitaciones.

Un tema pendiente en relación al área de los derechos es el consentimiento informado, refiérese al derecho a ser informado y luego a decidir sobre cómo enfrentar una patología determinada. Este problema se vincula con la sobrecarga en la atención publica ya que la gente no se da el tiempo para explicarle a la gente lo que tiene, y esa es la pelea entre los directivos del hospital y los clínicos si se puede decir pelea...darse el tiempo para enseñar y educar a la gente y explicarle cuáles son sus derechos (HEP-F). Ello permite que el paciente pueda tomar una decisión con conocimiento, sobre los tratamientos que deben realizar, y dentro de esa decisión se encuentra la libertad de elegir, por ejemplo sobre hacer una quimioterapia o no hacerla. El derecho al ejercicio del consentimiento informado, genera inquietud en los clínicos cuestionando la capacidad del paciente de discernir adecuadamente sobre las acciones a tomar. Sin embargo, en la medida que "los clínicos" informen adecuadamente, la capacidad de discernimiento debería ser amplio y no limitado.

Desde la ciudadanía el tema se relata a través del reconocimiento de la salud como un derecho constitucional, y por ello la atención de la salud no es lo máximo que se podría esperar, ya que no es una meta a alcanzar, sino un mínimo a cumplir. Conscientes de sus derechos, ejercen acciones para mejorar las condiciones, por ejemplo, a nivel primario: una reexaminación debe durar mas o menos 20 minutos por paciente, cosa que el paciente salga y que el doctor lo haya revisado, con estetoscopio..., eso fue algo que también se reclamó y se pudo lograr que los doctores atendieran mas o menos 20 minutos por paciente (HEP-C). Y en relación al Plan AUGE ejercen su derecho a la información generando acciones concretas: a la gente del Adulto Mayor los citamos a tal día, le pedimos a la doctora y a 
Alejandra que nos haga una exposición y que les expliquen a la gente cuáles son las nuevas medidas para que la gente sepa sus deberes y derechos. (CAN-C).

Finalmente como se puede apreciar en el esquema $\mathrm{n}^{\circ} 1$ todos los actores consideran la salud como un derecho, sobre la que se puede reclamar, informar y rectificar cursos de acción, sin hacer la distinción si se refiere al acceso o a la salud misma como estado de no enfermedad.

\section{ESQUEMA $N^{\circ}$ I. Percepción de los actores sobre el ejercicio de los} derechos en salud

\begin{tabular}{|c|c|c|c|}
\hline \multirow[b]{3}{*}{$\begin{array}{l}\text { Actores: } \\
\text { Sociedad } \\
\text { Civil }\end{array}$} & \multicolumn{2}{|c|}{ Nivel de atención: Terciario } & \multirow[b]{3}{*}{$\begin{array}{c}\text { Actores: } \\
\text { Sector } \\
\text { público }\end{array}$} \\
\hline & $\begin{array}{l}\text { la salud es un derecho } \\
\text { constitucional }\end{array}$ & $\begin{array}{l}\text { darle a conocer sus dere- } \\
\text { chos, usted tiene derechos a } \\
\text { reclamar y a información }\end{array}$ & \\
\hline & $\begin{array}{l}\text { le pedimos a la doctora } \\
\text { que haga una exposición y } \\
\text { que les expliquen a la gente } \\
\text { cuales son las nuevas medi- } \\
\text { das- Plan Auge- para que } \\
\text { la gente sepa sus deberes y } \\
\text { derechos }\end{array}$ & $\begin{array}{l}\text { cada vez los pacientes } \\
\text { conocen más sus derechos, } \\
\text { y exigen más, pero no } \\
\text { tengo como cubrir toda la } \\
\text { demanda }\end{array}$ & \\
\hline
\end{tabular}

Dicho reconocimiento común sobre la salud como derecho permite avanzar, sin mayores cuestionamiento, en la generación de acciones de tipo informativo / formativo, ejerciéndose así el primer nivel de la participación en el ámbito de la salud.

\subsection{Sobre el ejercicio de deberes ciudadanos en salud}

Sobre el tema de los deberes ejercidos en salud, existe una mayor disparidad de opiniones, por no existir una clara y común definición de los mismos, siendo la ciudadanía quién ha avanzado en la significación de tal concepto. 
Desde el nivel terciario, el tema de los deberes de los pacientes no está asumido por los mismos, a juicio de los funcionarios, por ejemplo los ciudadanos se comprometen a estar pero no están, el año pasado en el compromiso que firmamos, el hospital se comprometía con ellos a darles clases de satisfacción usuaria, a la carta de derechos del paciente, a visitarlos en sus organizaciones, darles los espacios ... y nosotros hicimos todo eso, ellos a lo que se habían comprometido era a venir a las reuniones, que vinieron y a poner gente de ellos en las oficinas de informaciones, y no cumplieron con eso... Si bien este incumplimiento puede explicarse por ser una actividad colectiva, donde se diluye en compromiso personal; sin embargo no se explica la misma actitud cuando es una conducta individual en beneficio propio cuando tú les das la hora para tres meses más, la gente la pierde (HEP-F). Bajo esta perspectiva el cumplimiento de los compromisos refleja el incumplimiento de los deberes de los pacientes, dificultándose la participación ciudadana.

Desde la ciudadanía que acude a nivel terciario se ha conceptualizado claramente el concepto y el accionar al respecto: tenemos deberes, con nosotros mismos, de responsabilidad, del autocuidado, de la promoción de la salud, y a eso estamos abocadas en este momento como dirigentes en el sector, trabajando en los consultorios con la Corporación de Salud, en la promoción de la salud y la prevención, y bueno, tratando de sensibilizar a la comunidad en este tema. Aunque tal claridad no es evidente en el nivel primario allí reclaman que todos nos hablan que tenemos deberes pero no nos dicen que tenemos derechos (HEP-C). No obstante, no siempre logran el accionar que conlleva el cumplimiento de los deberes, ni de los derechos.

ESQUEMA $N^{\circ}$ 2. Percepción de los actores sobre el ejercicio de los deberes en salud

\begin{tabular}{|c|c|c|c|}
\hline \multirow{4}{*}{$\begin{array}{l}\text { Actores: } \\
\text { Sociedad } \\
\text { Civil }\end{array}$} & \multicolumn{2}{|c|}{ Nivel de atención: Terciario } & \multirow{3}{*}{$\begin{array}{l}\text { Actores: } \\
\text { Sector } \\
\text { publico }\end{array}$} \\
\hline & $\begin{array}{l}\text { tenemos deberes, con noso- } \\
\text { tros mismos }\end{array}$ & $\begin{array}{l}\text { los ciudadanos se com- } \\
\text { prometen a estar pero no } \\
\text { están }\end{array}$ & \\
\hline & $\begin{array}{l}\text { todos nos hablan que te- } \\
\text { nemos deberes pero no } \\
\text { nos dicen que tenemos } \\
\text { derechos }\end{array}$ & $\begin{array}{l}\text { solo tenemos obligaciones } \\
\text { nosotros }\end{array}$ & \\
\hline & \multicolumn{2}{|c|}{ Nivel de atención: Primaria } & \\
\hline
\end{tabular}


Como se puede apreciar en esquema $\mathrm{n}^{\circ} 2$ no todos los actores consideran de igual manera el tema de los deberes ciudadanos en salud, solo existe una clara visión de los mismos en el nivel terciario y definido por la propia sociedad.

La significación atribuida a los deberes desde la sociedad civil tiene relación con su propio cuidado, y el compromiso esta centrado en "sí mismo". La comprensión de los deberes desde los funcionarios esta en la acción de asistir a los compromisos asumidos. Por consiguiente, se observan significaciones distintas, que desembocan en acciones diferentes, por un lado las acciones son hacia el autocuidado, y por otro son hacia la institucionalidad, generándose dinámicas de participación limitadas.

\subsection{Sobre la representatividad ciudadana en salud}

El tema de la representatividad ciudadana es central en el análisis de la participación, las posibilidades institucionales y las respuestas desde la sociedad civil son disímiles. A nivel gubernamental se solicita la creación del Consejo de Desarrollo Local (CDL) para el nivel primario, y para los hospitales se solicita prioritariamente la creación del Consejo Consultivo de Usuarios (CCU) y en segundo lugar el CDL.

El Consejo Consultivo del CABL se compone por representantes de la comunidad organizada que son cinco, representantes de los funcionaros que son dos, y ambos grupos fueron elegidos en votación universal, ese fue el procedimiento que se hizo. $Y$ aparte de esos están los miembros del equipo directivo... . Son cinco titulares y cinco suplentes, o sea los cinco titulares son los que vienen a las reuniones y cinco suplentes que suplen si el titular no está. De los trabajadores es igual, son dos titulares y dos suplentes. Del equipo directivo solo existen los titulares (HBL-F).

Como su nombre lo indica el CCU es de carácter consultivo. La periodicidad de las reuniones se establece en cada institución. Este año ya nos hemos reunido dos veces, por que nos reunimos en una primera reunión para ver el tema del compromiso, el análisis de las solicitudes ciudadanas del año pasado y las estrategias de abordaje. $Y$ nos reunimos en una segunda oportunidad para darles a conocer el plan estratégico del complejo, para que ellos dieran sus sugerencias y sus indicaciones" (HBL-F).

En el Hospital El Pino, primero surgió el CDL y desde esa instancia de participación ciudadana pretendemos este año poder hacer el Consejo Consultivo de Usuario, que nosotros no lo tenemos formado. La conformación del CDL fue iniciativa de la 
encargada del tema, así hice un grupo de...una masa critica de gente que empezó a asistir y que cada uno de ellos se organiza... con la poca gente que llega es con la que tienes que trabajar. Se juntan una vez al mes y de manera participativa deciden los cursos de acción futuros, por ejemplo ahora les voy a pasar el tema de cómo formamos el Consejo Consultivo, que den tres propuestas por grupo, ... ellos me escriben como creen ellos que debe ser y después sancionamos, y así lo hacemos, cosa que sea la misma comunidad la que me diga, (HEP-F).

El CDL de El Pino esta compuesto fundamentalmente por dirigentes vecinales, que están bien organizados, son señoras que tienen años, todos estos alrededores fueron tomas, entonces ellas saben trabajar, saben que consultorios les pertenece. El CDL del CABL presenta una conformación similar donde los que participan son los viejitos, los clubes de ancianos, los clubes de adulto mayor; la mayoría son adulto mayor, centros de madres, pero son todos viejitos (HEP-F).

A nivel primario la relación con la población es más cercana, un ejemplo de ello es el CDL del CESFAM La Feria. El CODESALFE es una instancia representativa de la población La Victoria. Hay un trabajo con la comunidad importante, pero mucho antes de que el tema se tratara desde el Ministerio. Yo diría que toda la vida hemos trabajado con la comunidad. No obstante, cuando se crea el Consejo de Salud, no fue agradable para todos los funcionarios porque siempre hay alguna reticencia: que no se metan en lo técnico, nosotros somos los que sabemos de lo técnico. Además se esta trabajando en la mesa informativa, se ven los reclamos, la cuenta pública la conversamos con la directiva del CODESALFE (CLF-F).

Sobre la representatividad del CODESALFE ésta es efectiva en relación a las organizaciones asistentes, en el mismo hay organizaciones de minusválidos, de deportes, etc. Pero grupos organizados, yo no estoy hablando de 'toda' la población. Es representativo de todos los grupos que existen aquí, organizados (CLF-F). En general en los CDL falta la presencia de los hombres y los jóvenes, ya que en su mayoría se componen de mujeres adultas con experiencia en trabajo con la comunidad.

Para los ciudadanos participantes en el Consejo Consultivo, se tiene una buena impresión de éste como instancia en la cual, como usuarios pueden dar a conocer sus inquietudes, propuestas y reclamos frente al funcionamiento y atención del Hospital. Por ejemplo, como representantes de la comunidad queremos aportar nuestras vivencias para que haya una comunicación del hospital hacia la comunidad, aterrizada, ir evaluando lo que esta haciendo e ir aportando nuestras vivencias, para que sea una cuestión que resulte realmente y a la vez sensibilizando a la 
población para que a la vez nos comprometamos con el cuento de la salud, que es un asunto que nos motiva bastante porque está muy carente la población de una salud digna (HEP-C).

Pero es en el CDL donde se ve claramente el objetivo fundamental de la ciudadanía siendo mejorar la calidad de vida de nuestras familias, y eso incluye salud, educación, mujeres como tema, deporte y cultura, medio ambiente y seguridad ciudadana, y hace cinco años que nos interesa enormemente (HEP-C).

A nivel primario los CDL lo conforman las organizaciones tanto territoriales como funcionales, las territoriales son las Juntas de Vecinos, las funcionales son Centros de Madres, Adultos Mayores, hay en el Consejo inscritas 18 organizaciones, nosotros también logramos el año pasado que Bomberos participara, y hay una representante de Bomberos que va a las reuniones, entonces la idea que cuando nosotros nos metimos al Consejo de Salud, la idea de nosotros era sacar el Consejo hacia la comunidad para que la gente conociera y supiera que existe un Consejo de Salud (CAN-C).

La historia fundacional de los CDL les ha permitido ser pioneros en la reglamentación que han diseñado: por haber sido el primero consejo conformado en este territorio... nosotros inventamos unos estatutos, o sea adecuamos los estatutos de los organismos funcionales y les hicimos unas modificaciones para que todos los consejos se rigieran por ese. Por ejemplo, en una parte dice son parte de este consejo todos los líderes de opinión con respaldo. O sea no necesariamente tienes que estar en una organización constituida sino que puedes ser un delegado de cuadra que tenga el respaldo de todos sus vecinos (CLF-C). De esta manera son legisladores y legitimados por sus propias organizaciones.

Tienen experiencia de liderazgo, de solidaridad, de organización y desde ese punto de vista quizás tengamos una cosa que no se equipara con otros consejos. Seguramente la trayectoria que han ido construyendo juntos les permite tener una estructura en el CODESALFE que tiene una mirada que sabe detectar problemas de salud, que sabe como resolverlos en conjunto. Y el desafió que se han planteado es cómo validamos eso, como darle una mayor participación todavía a nuestras organizaciones, eso es lo que nos falta. Porque ellas tienen potencialmente muchas capacidades, uno las ve que son personas y lideres muy valiosas, con una gran convicción, con un gran sentido social respecto de ayudarse unas a otras. (CLF-C).

Como se puede apreciar en esquema $n^{\circ} 3$ todos los actores tienen incorporado la necesidad de funcionar en conjunto con la comunidad representada a través de 
organismos como el CCU o el CDL. Sin embargo, el CDL por su vinculación directa con la comunidad es una instancia de participación superior que los CCU.

\section{ESQUEMA N 3. Percepción de los actores sobre la representatividad ciudadana en salud}

\begin{tabular}{|c|c|c|c|}
\hline \multirow{4}{*}{$\begin{array}{l}\text { Actores: } \\
\text { Sociedad } \\
\text { Civil }\end{array}$} & \multicolumn{2}{|c|}{ Nivel de atención: Terciario } & \multirow{4}{*}{$\begin{array}{l}\text { Actores: } \\
\text { Sector } \\
\text { público }\end{array}$} \\
\hline & $\begin{array}{l}\text { los representantes de la co- } \\
\text { munidad queremos aportar } \\
\text { nuestras vivencias para que } \\
\text { haya una comunicación del } \\
\text { hospital hacia la comunidad, } \\
\text { aterrizada, ir evaluando lo } \\
\text { que esta haciendo e ir apor- } \\
\text { tando nuestras vivencias }\end{array}$ & $\begin{array}{l}\text { conversamos acerca de qué } \\
\text { queremos nosotros que sea } \\
\text { el hospital, y para donde } \\
\text { ellos quieren que vaya el } \\
\text { hospital también, cuales son } \\
\text { las demandas ciudadanas } \\
\text { en ese ámbito (CDL) }\end{array}$ & \\
\hline & $\begin{array}{l}\text { existe una estructura en el } \\
C D L \text { que tiene una mirada } \\
\text { que sabedetectarproblemas } \\
\text { de salud, que sabe como } \\
\text { resolverlos en conjunto }\end{array}$ & $\begin{array}{l}\text { Hay un trabajo con la } \\
\text { comunidad importante, } \\
\text { pero mucho antes de que } \\
\text { el tema se tratara desde el } \\
\text { Ministerio }\end{array}$ & \\
\hline & \multicolumn{2}{|c|}{ Nivel de atención: Primaria } & \\
\hline
\end{tabular}

De esta manera la representatividad es la primera condición que se establece de manera institucional para canalizar la participación, dicha institucionalidad no constituye un fin en si mismo, típico de las democracias formales, sino que es comprendido como el canal para incidir en la toma de decisiones, o al menos en la construcción de una participación de tipo consultiva.

\subsection{Sobre los recursos públicos y ciudadanos en salud}

El tema sobre la disponibilidad de recursos en el área de salud interfiere directamente con los objetivos a lograr en participación. Refieren a la falta de recursos tanto humanos como de infraestructura ${ }^{18}$, no así materiales (insumos). Por ejemplo,

${ }^{18}$ Tenemos deficiencias físicas que hacen que la atención sea, por ejemplo el Servicio de Urgencia, no 
en uno de los hospitales se expresa que necesitamos más médicos, necesitamos más espacio físico, o sea nosotros estamos dispuestos a atender, pero con más recursos humanos (HEP-F). De hecho la falta de recursos humanos es uno de los topes para procesar los reclamos en las OIRS. La escasez de personal médico repercute en la posibilidad de dar cumplimiento acabado a los requisitos de una participación efectiva, si se retoma el tema de los derechos es casi inviable ejercer el consentimiento informado; los médicos expresan que quieres que haga si tengo 20 pacientes en una hora, no me voy a poner a darle explicaciones (HEP-F). Agravándose dicha situación por la incorporación de mas tareas (Plan AUGE) manteniendo la misma dotación.

No obstante, la limitación señalada, se han organizado institucionalmente y han realizado un convenio con una empresa telefónica ${ }^{19}$, a través del cual aportan regularmente recursos, los que son destinados al área de participación, específicamente a capacitación.

En el nivel primario de atención, la escasez de recursos es también una realidad, partiendo por la falta de espacio y su deficiente infraestructura, desde los baños hasta el mismo edificio (CAN-F). Esto se ve agravado por las exigencias que implica el AUGE para la atención primaria, así como con el aumento de la demanda (tanto en magnitud, como en términos de una mayor exigencia de parte de la población) (CLF-F) El financiamiento que aporta el Plan AUGE, corresponde a los medicamentos, pero no se ha aumentado la dotación de enfermeras, médicos, etc. (CLF-F). Tal es el déficit, que los propios funcionaros realizan actividades tratando de resolver la situación: incluso nosotros mismos cooperamos con plata de nuestros bolsillos para tener muebles de trabajo y adecuar la sala para atender decentemente, el material con el que trabajamos también lo costeamos nosotros. (CAN-F)

El financiamiento para actividades relativas a la participación viene dada fundamentalmente por recursos municipales, siendo éstos entregados cada dos meses por la administración comunal de Pedro Aguirre Cerda, donde se reciben $\$ 20.000$ destinados a su área -participación-, dinero que evidentemente no alcanza para nada (CAN-F)

tiene una sala de espera adecuada para la cantidad de pacientes que atiende, lejos le quedo chico al tipo que evaluó el tema cuando lo hicieron, es una sala de espera miserable" (HEP-F).

19 Nosotros tenemos un contrato con una empresa privada, la telefónica, que tiene teléfonos públicos, y nosotros de ahí sacamos, porque nosotros hicimos un contrato que ellos no tienen que dar una plata del teléfono público, del chaucheo, y por ahí ganamos un poco de plata (HEP-F). 
La mirada de la sociedad civil participante en los consejos es notoriamente más comprensiva frente a la escasez de recursos, y hasta propositiva. Yo me di cuenta que una cosa es la idea que tiene la comunidad afuera y otra cosa es como te funcionan los hospitales, o sea, de repente te das cuenta que los hospitales no pueden hacer más, y la gente cree que no es así, la gente demanda, que tienes que atenderla y que tienes que atenderla, pero realmente con lo que cuentan los hospitales es mínimo, y yo creo que también es responsabilidad de cada uno de nosotros aportar tu granito de arena en la parte social. (HEP-C)

En el consultorio La Feria utilizan los recursos recibidos por el municipio para incentivar un poco más el trabajo que están haciendo las distintas organizaciones $(C L F-C)$, y la gente hace maravillas con los 30 mil pesos que se les dan. Cumplen con las exigencias, incluyen los factores protectores, cumplen con todas las condicionantes del programa. (CLF-C). Ello no significa que no sean concientes de la situación en la que se encuentra el consultorio, éste terminó su vida útil en términos de infraestructura. Entonces hoy día vienen lineamientos desde el ministerio, como por ejemplo la sectorización de la salud o el plan AUGE, la reforma de la salud y todas las cosas se hacen a medias porque no tenemos la infraestructura física ni humana que corresponde (CLF-C).

ESQUEMA $N^{\circ}$ 4. Percepción de los actores sobre la disponibilidad de recursos en salud

\begin{tabular}{|c|c|c|c|}
\hline \multirow{4}{*}{$\begin{array}{l}\text { Actores: } \\
\text { Sociedad } \\
\text { Civil }\end{array}$} & \multicolumn{2}{|c|}{ Nivel de atención: Terciario } & \multirow{4}{*}{$\begin{array}{l}\text { Actores: } \\
\text { Sector } \\
\text { publico }\end{array}$} \\
\hline & $\begin{array}{l}\text { realmente con lo que cuentan } \\
\text { los hospitales es mínimo, y yo } \\
\text { creo que también es responsa- } \\
\text { bilidad de cada uno de nosotros } \\
\text { aportar tu granito de arena en } \\
\text { la parte social }\end{array}$ & $\begin{array}{l}\text { tenemos una planta de } \\
\text { personal menor a la que } \\
\text { deberíamos tener por la } \\
\text { cantidad de personas } \\
\text { que tenemos, eso está } \\
\text { más que claro }\end{array}$ & \\
\hline & $\begin{array}{l}\text { hoy día vienen lineamientos } \\
\text { desde el ministerio, como por } \\
\text { ejemplo la sectorización de la } \\
\text { saludo el plan Auge, la reforma } \\
\text { de la salud y todas las cosas } \\
\text { se hacen a medias porque no } \\
\text { tenemos la infraestructura física } \\
\text { ni humana que corresponde }\end{array}$ & $\begin{array}{l}\text { la principal carencia es } \\
\text { de recursos humanos e } \\
\text { infraestructura. Lo cual } \\
\text { se ve agravado con las } \\
\text { exigencias que implica el } \\
\text { AUGE para la atención } \\
\text { primaria }\end{array}$ & \\
\hline & \multicolumn{2}{|c|}{ Nivel de atención: Primaria } & \\
\hline
\end{tabular}


Finalmente como se puede apreciar en el esquema $\mathrm{n}^{\circ} 4$ todos los actores están de acuerdo en el impedimento que significa la escasez de recursos para el cumplimiento de los derechos ciudadanos en salud. Sin embargo, la sociedad civil presenta una actitud menos crítica al respecto, posiblemente porque viven en contextos carenciados y han generado recursos resilentes para convivir con la escasez.

La paradoja que se presenta tiene relación con una participación instalada en contextos de escasez institucional, donde el Estado debería generar las condiciones materiales y humanos para el ejercicio de la misma, y no logra proveerlo, pero a su vez estresa a sus funcionarios con metas de mayor apertura a la comunidad. Siendo finalmente la comunidad la que "comprende y disculpa" el contexto de escasez institucional.

\subsection{Sobre la toma de decisiones en salud}

La quinta dimensión del análisis se vincula con la modalidad desarrollada para la toma de decisiones, lo cual es determinante del tipo de participación pasiva o activa que se ejerce en salud.

En los hospitales, dada la existencia de la instrucción para la conformación de Consejos Consultivos, la toma de decisión en conjunto es dificultosa; por una parte porque no es condición para el funcionamiento del Consejo, pero por otra por el nivel de organización de la sociedad civil. A pesar que se intenciona dicha participación la, condición es que ellos tienen que ser capaces de saber qué es lo que quieren, pero ... son súper desordenados, yo digo que lata porque en el fondo se nota, se nota que son desordenados, entonces cuando tu tomas decisiones a nivel jerárquico o a nivel de estructura, tu puedes eludirlos porque no los ves con el poder que deberían tener (HEP-F).

Las expectativas de participar en la toma de decisiones constituye una referencia para los funcionarios, a nivel primario ya que en algún minuto se pensaba que... por ejemplo, como en otros países en algunos consultorios dentro del comité técnico había un representante de la comunidad. Yo creo que a ese nivel, no, no estamos preparado (CLF-F). Si bien la toma de decisiones en conjunto aun no es viable, se rescata que hay un trabajo previo e importante con la comunidad, pero mucho antes de que el tema se tratara desde el Ministerio... toda la vida hemos trabajado con la comunidad. Siendo ésta la mejor condición para generar un proceso más participativo, ya que el acercamiento a la comunidad es desde la comunidad misma. El consultorio La Feria fue construido por los propios pobla- 
dores, en el año 52, cuando nace la población La Victoria con la toma. Por esta razón, las personas sienten orgullo por el consultorio así como también un sentido de pertenencia (CLF-F).

Para la sociedad civil que participa en el nivel terciario de salud, el tema de la toma de decisiones esta detenido, y ello se debe a la concepción de superioridad que tienen los doctores, porque de hecho hay como una contradicción entre el usuario y el profesional de la salud, porque claro, como el médico es el que sabe no ve la necesidad de escuchar al paciente, ese es en el proceso que estamos.. Por ahora está el proceso y la participación es sólo formal. (HEP-C). Además de la perspectiva medica, como limitante de la toma de decisiones en conjunto existe un problema de acostumbramiento en la relación entre los doctores, directivos y los usuarios, y nosotros como sus representantes. Igual se nos entregan copias de la cuenta pública, pero no hay incidencia en el proceso porque es muy vertical la decisión, no se escucha a la base como nosotros lo hacemos en los centros de salud locales (HBL-C).

Distinta es la percepción desde la sociedad civil, del proceso participativo en el nivel de atención primaria. En ese sentido, en los centros de salud familiar- los antiguos consultorios- nosotros tenemos una participación real porque hay más horizontalidad en las decisiones y una comunicación más pareja entre la directora de nuestro centro y nosotros en las reuniones periódicas; muy distinto a como es la cosa acá hoy por hoy (HEP-C).

Probablemente dicho proceso participativo se vincule con el hecho que el consultorio fue formado de abajo pa' arriba y no de arriba pa' abajo, o sea desde los mismos pobladores, entonces el sentimiento de pertenencia que hay es muy fuerte $^{20}$ (CLF-C).

Finalmente como se puede apreciar en el esquema $n^{\circ} 5$ la toma de decisiones en conjunto tiene matices dependiendo desde donde se ubique en el nivel de atención de salud, siendo mucho mas viable en el nivel local - primario, que en el terciario.

20 Pero ahí mismo en el terreno donde estaba la escuela, estaban las carpas de la cruz roja. De alli comienza a gestarse, desde los mismos pobladores, el tema del consultorio. Se deja el espacio y se construye. Venía una sola enfermera con un médico en principio. Luego empezó a tomar cuerpo y a trasladarle al gobierno y toda la cosa para que funcionara. Nosotros siempre hablamos de mi consultorio, mi vecino, mi pasaje (CLF-C). 


\section{ESQUEMA N 5 . Percepción de los actores sobre la toma de decisiones ciudadanas en salud}

\begin{tabular}{|c|c|c|c|}
\hline \multirow{4}{*}{$\begin{array}{l}\text { Actores: } \\
\text { Sociedad } \\
\text { Civil }\end{array}$} & \multicolumn{2}{|c|}{ Nivel de atención: Terciario } & \multirow{4}{*}{$\begin{array}{l}\text { Actores: } \\
\text { Sector } \\
\text { público }\end{array}$} \\
\hline & $\begin{array}{l}\text { no hay incidencia en el proceso } \\
\text { porque es muy vertical la deci- } \\
\text { sión, no se escucha a la base } \\
\text { como nosotros lo hacemos en } \\
\text { los centros de salud locales }\end{array}$ & $\begin{array}{l}\text { cuando tu tomas deci- } \\
\text { siones a nivel jerárquico } \\
\text { o a nivel de estructura, tu } \\
\text { puedes eludirlos porque } \\
\text { no los ves con el poder } \\
\text { que deberían tener }\end{array}$ & \\
\hline & $\begin{array}{l}\text { Esto venia de arriba, y a noso- } \\
\text { tros nos molesto porque somos } \\
\text { nosotros los que estamos traba- } \\
\text { jando, o sea que nos pregunten } \\
\text { si estamos de acuerdo de que la } \\
\text { forma en que van a trabajar }\end{array}$ & $\begin{array}{l}\text { Yo creo que a ese } \\
\text { nivel, no, no estamos } \\
\text { preparado }\end{array}$ & \\
\hline & \multicolumn{2}{|c|}{ Nivel de atención: Primaria } & \\
\hline
\end{tabular}

El proceso de ingerencia en la toma de decisiones efectivamente responde a la cercanía y confianza entre los funcionarios y la comunidad, relación construida a lo largo del tiempo, relación con ingerencia desde los inicios de los consultorios. Dicha relación pierde posibilidades en el nivel terciario de salud, por la lejanía, el anonimato y aun más por la incapacidad de articular demandas en conjunto, desde la sociedad civil.

\section{Conclusión}

Si la participación es la necesidad de empoderamiento por parte de la ciudadanía para ejercer un rol activo sobre las políticas y medidas gubernamentales que se diseñan, ejecutan y evalúan, y se refieren a sus intereses cotidianos, sin duda que la salud es un área donde el empoderamiento debe ser un camino claramente marcado, tanto desde el Estado como desde la ciudadanía. Ahora bien, esta senda se camina paulatinamente, y para llegar a dicha meta es importante conocer en qué punto está hoy el trayecto recorrido. Si se recogen los antecedentes del análisis antes desarrollado, donde se observaron las miradas de los actores y los 
niveles institucionales sobre las categorías referidas a la participación y se trata de adjudicar a dichas percepciones un tipo de participación según la gradiente antes presentada, se pueden observar los resultados de la tabla $\mathrm{n}^{\circ} 2$.

\section{TABLA N $N^{\circ}$ 2. Estado de la participación en el área de la salud}

\begin{tabular}{|c|c|c|c|c|c|}
\hline Categorías & $\begin{array}{c}\text { Derechos } \\
\text { ciudadanos }\end{array}$ & $\begin{array}{c}\text { Deberes } \\
\text { ciudadanos }\end{array}$ & $\begin{array}{c}\text { Representatividad } \\
\text { ciudadana }\end{array}$ & Recursos & $\begin{array}{c}\text { Toma de decisión } \\
\text { conjunta }\end{array}$ \\
\hline $\begin{array}{c}\text { Funcionarios } \\
\text { nivel terciario }\end{array}$ & $\begin{array}{c}\text { información } \\
\text { II }\end{array}$ & $\begin{array}{c}\text { instrumental } \\
\text { II }\end{array}$ & $\begin{array}{c}\text { consultiva } \\
\text { III }\end{array}$ & $\begin{array}{c}\text { instrumental } \\
\text { I }\end{array}$ & $\begin{array}{c}\text { consultivo } \\
\text { III }\end{array}$ \\
\hline $\begin{array}{c}\text { Funcionarios } \\
\text { nivel primario }\end{array}$ & $\begin{array}{c}\text { instrumental } \\
\text { I }\end{array}$ & $\begin{array}{c}\text { instrumental } \\
\text { I }\end{array}$ & $\begin{array}{c}\text { gestionaría } \\
\text { IV }\end{array}$ & $\begin{array}{c}\text { instrumental } \\
\text { I }\end{array}$ & $\begin{array}{c}\text { consultivo } \\
\text { III }\end{array}$ \\
\hline $\begin{array}{c}\text { Representantes } \\
\text { nivel terciario }\end{array}$ & $\begin{array}{c}\text { empoderamiento } \\
\text { VI }\end{array}$ & $\begin{array}{c}\text { gestionaría } \\
\text { IV }\end{array}$ & $\begin{array}{c}\text { accountability } \\
\text { V }\end{array}$ & $\begin{array}{c}\text { gestionaría } \\
\text { IV }\end{array}$ & $\begin{array}{c}\text { consultivo } \\
\text { III }\end{array}$ \\
\hline $\begin{array}{c}\text { Representantes } \\
\text { nivel primario }\end{array}$ & $\begin{array}{c}\text { informativa } \\
\text { II }\end{array}$ & $\begin{array}{c}\text { consultiva } \\
\text { III }\end{array}$ & $\begin{array}{c}\text { empoderamiento } \\
\text { VI }\end{array}$ & $\begin{array}{c}\text { gestionaría } \\
\text { IV }\end{array}$ & $\begin{array}{c}\text { consultivo } \\
\text { III }\end{array}$ \\
\hline
\end{tabular}

Fuente: Elaboración propia.

El proceso participativo es dinámico, varia desde la perspectiva que se lo mire, y no es univoco. No obstante, se pueden apreciar que:

- A nivel de la ciudadanía existe una mayor percepción sobre el desarrollo de la participación, tanto sobre el deber ser de la misma como sobre la situación actual.

- A nivel de los funcionarios existe una percepción sobre un menor desarrollo ciudadano, dado que refieren a niveles inferiores de la gradiente, y posiblemente se atribuya al temor al cambio organizacional.

Si este análisis se vincula con la tabla $\mathrm{n}^{\circ} 1$ donde se desarrolla la gradiente según las indicaciones ministeriales sobre los tres objetivos contenidos en los Compromisos de Gestión sobre Participación. Allí se observa que están presentes todos los niveles de la gradiente, pero con menor desarrollo los tres últimos (gestionaria, accountability, "empoderamiento"). 
Entones la triada del análisis se compone por la normativa institucional; la implementación institucional (representada por los funcionarios) y el ejercicio ciudadano. El balance de esta trirelación desemboca en lo siguiente:

- La normativa institucional delimita los espacios de participación (los tres objetivos) pero dentro de dicha delimitación permite que se despliegue la gradiente en todos sus niveles.

- La implementación institucional tiene dos niveles de profundidad. En la atención hospitalaria solo llegan al nivel consultivo. Y en la atención primaria, llegan hasta la cogestión. Evidentemente en el primer caso el desarrollo del tema participativo es menor y se ha incorporado como un requisito ministerial (desde arriba). La práctica participativa en los consultorios es de largo tiempo, y la cercanía con la comunidad sin duda, genera un espacio de presión mayor por ingerir en los temas de salud.

- La ciudadanía es la misma en ambos niveles institucionales. Pero por un lado no logran expresar sus demandas en la constitución de un colectivo mayor para participar en el nivel terciario. Posiblemente debido a la concurrencia de múltiples organizaciones de diferentes comunas. Por otro lado, cuando logran organizarse expresan sus inquietudes y tratan de ir un paso más allá, hacia el empoderamiento en el sector salud. Claramente esto se observa en el nivel primario, no siendo casual que los consultorios estudiados hayan sido creados por iniciativa de la comunidad misma. Nacieron como una necesidad desde abajo.

Por consiguiente, estos tres niveles del análisis, permiten afirmar que el tema de la participación no se puede abordar ni desde un enfoque institucional, ni pluralista, ni societario, solamente, porque la salud es un bien común que requiere la transdisciplinariedad para comprenderlo, orientarlo y acompañarlo en todos sus matices.

Finalmente si se debieran realizar recomendaciones para la implementación de las políticas participativas en salud, se debería tener presente lo siguiente:

- En relación a la normativa institucional: considerar que las orientaciones de las mismas puedan abarcar toda la variedad y particularidad de los niveles de atención, tanto central, regional como local.

- En relación a la implementación: considerar la sobre perspectiva biomédica de los funcionarios de salud, y generar instancias de capacitación que aporten 
elementos para comprender el proceso participativo ciudadano, tanto sea que deban generarlo, fortalecerlos o desarrollarlo. Y acompañar con recursos específicos que permitan asumir las nuevas responsabilidades que la normativa indica cumplir.

- En relación a la ciudadanía: considerar la trayectoria participativa de la comunidad, a fin de acompañar el proceso requerido para desarrollarla, teniendo presente que no es una obligación del estado el desarrollo de la ciudadanía, sino de la propia sociedad civil.

\section{Anexo}

Distribución de la muestra e identificación para el análisis

\begin{tabular}{|l|c|c|c|c|}
\hline Tipo de Institución & $\begin{array}{c}\text { Número de } \\
\text { Entrevistados } \\
\text { Funcionarios }\end{array}$ & $\begin{array}{c}\text { Código de } \\
\text { identificación }\end{array}$ & $\begin{array}{c}\text { Número de Entrevista- } \\
\text { dos representantes de } \\
\text { la comunidad, en los } \\
\text { Consejos }\end{array}$ & $\begin{array}{c}\text { Código de } \\
\text { identificación }\end{array}$ \\
\hline Hospital El Pino & 2 & $\mathrm{HEP}-\mathrm{F}$ & $1^{21}$ & $\mathrm{HEP}-\mathrm{C}$ \\
\hline $\begin{array}{l}\text { Complejo Asiten- } \\
\text { cial Barros Luco } \\
\text { (hospital) }\end{array}$ & 2 & $\mathrm{HBL}-\mathrm{F}$ & 3 & $\mathrm{HBL}-\mathrm{C}$ \\
\hline $\begin{array}{l}\text { CESFAM Amador } \\
\text { Neghme }\end{array}$ & 2 & $\mathrm{CAN}-\mathrm{F}$ & 2 & $\mathrm{CAN}-\mathrm{C}$ \\
\hline CESFAM La Feria & 1 & $\mathrm{CLF}-\mathrm{F}$ & 3 & $\mathrm{CLF}-\mathrm{C}$ \\
\hline Total entrevistados & \multicolumn{2}{|c|}{7} & \multicolumn{2}{|c|}{} \\
\hline
\end{tabular}

Fuente: elaboracion propia.

${ }^{21}$ Se realizó una entrevista grupal (cinco participantes) con los representantes de la comunidad en el Consejo. 


\section{Bibliografía}

Canales, A. y Márquez, R. (2006), "Una propuesta para el fortalecimiento del rol de la participación social en al superación de la pobreza". En: Umbrales Sociales 2006. Santiago, FUNASUPO.

Canto, R. (2000), "Políticas Públicas: Más allá del pluralismo y la participación ciudadana". Revista Gestión y Política Publica, Vol IX, Numero 2.

Celedón, C. y NoÉ, M. (2000), "Reformas del sector de la salud y participación social"; Organización Panamericana de la Salud, Revista Panamericana de Salud Pública2. En: www.paho.org/spanish/dbi/es/ARTI—Celedon.pdf.

de la Maza, G. (2004), "Política Sociedad Civil en Chile: El caso de las Políticas Sociales (1990-2004)". Programa Ciudadanía y Gestión Local. Revista Política № 43, Primavera.

Donoso, N. (2004), "Estrechando vínculos con la ciudadanía". Ministerio de Salud del Gobierno de Chile, División Gestión de Red Asistencial, Unidad de Participación Social. Santiago. En: www.lachsr.org/observatorio/Brasilia/pdf/ NoraDonoso_texto.pdf

Escobar Riffo, D. (2001), "La participación de la ciudadanía en los programas de promoción de la salud". Documento preparado en el marco del seminario de grado "Modernización y desigualdad social" dictado por el profesor Raúl Urzúa. Universidad de Chile, Facultad de Ciencias Sociales, Departamento de Sociología. Mimeo. En: http://www.innovacionciudadana.cl/ddt/dcto8.pdf.

EzPINOZA, V. (2004), "De la Participación Social a la Participación en un Nuevo Contrato de Ciudadanía". Revista Política N 43, Primavera, pp. 149-183.

Garces, M. y Valdes, A. (1999), "Estado del Arte de la Participación Ciudadana en Chile". En: http://www.asesoriasparaeldesarrollo.cl/

LARRAín, S. (2001), "Participación ciudadana y salud", En: http://www.paho.org/ English/HDP/HDW/citizenparticipation.pdf.

MarCh, J. Olsen; Vergara (1997), El redescubrimiento de las instituciones: la base organizativa de la política. Ed. FCE. 
Marshall, M. T., Sáenz, M. y Sallnas J. (1990), Participación en Salud: Lecciones y Desafíos. Corporación de Salud y Políticas Sociales. Santiago, CORSAPS, 1990.

Marshall, T. H. y Bottomore, T. (2005), Ciudadanía y Clase Social. Buenos Aires, Ed. Losada.

Orellana, R. y Celedón, C. (2003), "Gobernancia y Participación Ciudadana. Equidady Salud:Foro Liderazgo" En:http://www.equidadensalud.org/foroliderazgo/ archivos/CeledonOrellana.pdf

Peters, G. (1995), "Modelos alternativos del proceso de la política pública: de abajo hacia arriba y de arriba hacia abajo"2. Revista Gestión y Política Pública, Vol. IV, № 2 .

RaCZYNSKI, D. y Serrano, C. (1998), "Lineamientos para Construir una Matriz de Indicadores de Participación Social en Programas Nacionales Participativos". Informe Final de Consultoria: Asesorías para el Desarrollo, Santiago. En: http:// www.asesoriasparaeldesarrollo.cl/

SSMS, (2006), "La Cuenta Pública de Servicios de Salud y Hospitales". Documento Interno - Mimeo, Santiago de Chile.

ReCCA, M. InES, et al (2007), "Participación ciudadana en salud: ¿̇proceso de cambios en desarrollo? Observatorio de Equidad de Género en Salud. Informe 2006". Santiago de Chile, OPS.

\section{Documentos del gobierno chileno y de otros organismos públicos:}

Gobierno de Chile, (2005a), "Agenda Pro Participación Ciudadana. Bachelet Michelle". Santiago, 29 de septiembre. En: http://www.fes.cl/documentos/PP/ agenda_p_ciudadana.pdf

- (2005), "Ley N 19.966, AUGE Régimen de Garantías en Salud", En: http// www.ben.cl

- (2004), "Ley 19.937 Autoridad Sanitaria. Publicada por el Diario Oficial el 24 de febrero del 2004" En: http//www.bcn.cl 
- (2000), "Instructivo Presidencial sobre Participación Ciudadana. Oficio № 030 del 07-12-2000". En: http// www.guíaweb.gob.cl/recursos/documentos.htm

MINSAL, (2006a), "Compromiso de Gestión N 7: Participación Social. Subsecretaria de Redes Asistenciales". Documento Interno - Mimeo. Santiago de Chile.

- (2006b), "La Cuenta Pública de Servicios de Salud y Hospitales". Documento Interno - Mimeo, 2006. Santiago de Chile.

- (2006c), "Modelo de Atención con Enfoque Familiar en Atención Primaria de Salud, División de Gestión de la Red Asistencial". Documento Interno - Mimeo. Santiago de Chile.

- (2006d), "Modelo de Salud Familiar para la APS y anexos. Memorandum C211/No 10, 2006". Documento Interno - Mimeo. Santiago de Chile.

- (2006e), "Objetivos Específicos sobre los Compromisos de Gestión Nํ7". División de Gestión de la Red Asistencial, Documento Interno - Mimeo, 2006. Santiago de Chile.

- (2006f), "Subsecretaria de Redes Asistenciales. Compromisos de Gestión 2006. Orientaciones metodológicas". Documento Interno - Mimeo. Santiago de Chile.

- (1986), "Reglamento Orgánico De Los Servicios de Salud (Deroga Decreto Supremo $N^{\circ} 42$ de 1986 Del Ministerio de Salud". Documento Interno - Mimeo. Santiago de Chile.

MSGP, (2001), Ministerio Secretaria General de la Presidencia (MSGP). Gobierno de Chile "Participación Ciudadana en la Gestión Pública". Santiago de Chile. pp 12-15.

- (2003), "Ley 19880. . Ministerio Secretaria General de la Presidencia, Gobierno de Chile". En: http://www.conicyt.cl/oirs/acerca/Ley_19880.doc

OPS/OMS, (2005), "Unidad de entornos locales, Área de desarrollo sostenible y salud ambiental: Gobernancia y participación ciudadana en la reforma de la salud." Organización Panamericana de la Salud en conjunto con la Organización Mundial de la Salud. En: http://www.paho.org/Spanish/AD/SDE/Desarrollo_Local_Cumbre_ELS_corregido.pdf. 
Sitios URL: Fecha de acceso: febrero a julio, 2007.

www.conicyt.cl

www.ben.cl

www.guíaweb.gob.cl

www.innovacionciudadana.cl

www.lachsr.org

www.minsal.cl

www.modernizacion.cl

www.paho.org

www.ssms.cl 